\title{
PERANCANGAN SISTEM INFORMASI FAKULTAS KEGURUAN DAN ILMU PENDIDIKAN BERBASIS WEB (STUDI KASUS : UNIVERSITAS VICTORY SORONG)
}

\author{
Iriene Surya Rajagukguk \\ email: irenerajagukguk1985@gmail.com
}

\begin{abstract}
Abstrak
Fakultas Keguruan dan Ilmu Pendidikan (FKIP) Universitas Victory Sorong adalah tempat untuk melanjutkan studi di tingkat Universitas setelah lulus dari Sekolah Menengah Atas. FKIP Universitas Victory Sorong terletak di JL. Basuki Rahmat, KM 11,5, Kelurahan Klawuyuk-Sorong, Papua Barat, adalah salah satu lembaga terbaik di kota Sorong. Namun dalam hal promosi masih merupakan masalah yang sangat penting karena masih menggunakan sistem perkenalan secara manual, yaitu dengan menggunakan brosur. Oleh karena itu sebuah website dibutuhkan yang terdiri dari beberapa komponen yang berhubungan dengan pemasaran FKIP itu sendiri. Metode yang digunakan dalam pengembangan dan desain sistem ini adalah metode waterfall. Proses metode waterfall yang pada pelaksanaan sistem dilakukan secara berurutan. Sehingga sistem yang dihasilkan akan berkualitas baik, karena pelaksanaannya secara bertahap sampai tidak terfokus pada tahapan tertentu. Website FKIP ini memudahkan siswa FKIP, dosen dan mahasiswa sendiri untuk mendapatkan informasi yang berhubungan dengan Universitas FKIP Victory Sorong.
\end{abstract}

Kata kunci: sistem informasi, promosi, waterfall.

\section{INFORMATION SYSTEMS DESIGN FACULTY OF TEACHER TRAINING AND EDUCATION WEB BASED (CASE STUDY: VICTORY UNIVERSITY SORONG)}

\begin{abstract}
Victory Sorong University Teaching and education faculty (FKIP) is a place to continue their studies at the College level after graduating from high school. FKIP Universitas Victory Sorong Located at JL. Basuki Rahmat, KM 11.5, Klawuyuk-Sorong village, west Papua, is one of the best institutions in Sorong City. But in terms of promotion is still a very important problem because it still uses the introduction system manually, namely by using brochures. therefore a website is needed which consists of several components related to FKIP marketing itself. The method used in the development and design of this system is the waterfall method. The process of the waterfall method that is on the execution of the system is done sequentially. So that the system produced will be of good quality, due to its implementation in stages until it is not focused on certain stages. This FKIP website makes it easy for FKIP students, lecturers and students themselves to get information related to FKIP Victory Sorong University.
\end{abstract}

Keywords: Information Systems, promotions, Waterfall. 


\section{PENDAHULUAN}

Informasi saat ini dapat diperoleh secara cepat dan akurat dengan menggunakan teknologi informasi. Internet sebagai salah satu media teknologi informasi sangat besar manfaatnya bagi masyarakat yang membutuhkan informasi, yang sebelumnya penyebaran informasi masih terhambat karena belum optimalnya pemanfaatan teknologi informasi. Pengelolaan informasi pada Fakultas Keguruan dan Ilmu Pendidikan (FKIP) Universitas Victory Sorong, dari segi promosi masih menjadi permasalahan yang sangat kompleks karena masih menggunakan sistem pengenalan secara manual yaitu dengan menggunakan brosur. Sebab itu dibutuhkan sebuah website yang di dalamnya terdiri dari beberapa komponen yang terkait dengan pengenalan FKIP itu sendiri. Peranan dari sebuah website sebagai alat bantu yang dapat menyalurkan informasi di lingkungan fakultas, universitas, dosen dan mahasiswa.

Berdasarkan penjelasan di atas, maka akan dilakukan penelitian dengan judul "Perancangan Sistem Informasi Fakultas Keguruan dan Ilmu Pendidikan Universitas Victory Sorong berbasis Web”. Sistem ini diharapkan dapat memudahkan siswa/siswi lulusan SMA/Sederajat atau siapapun yang ingin mencari segala informasi yang berkaitan dengan FKIP Universitas Victory Sorong.

\section{KAJIAN DAN TEORI}

Teori yang digunakan dalam penelitian ini adalah teori Pressman 2015 menggunaan rancangan waterfall dalam Perancangan Sistem Informasi Fakultas Keguruan dan Ilmu Pendidikan Universitas Victory Sorong berbasis Web dengan

\section{METODE DAN PERANCANGAN SISTEM}

\subsection{Tinjauan Umum}

Universitas Victory Sorong. Alamat lokasi penelitian Jl. Basuki Rahmat, Km. 11,5, Klasaman, Klawuyuk Sorong, Papua Barat. Penelitian ini yang menjadi objek adalah Fakultas Keguruan dan Ilmu Pendidikan Universitas Victory Sorong. Dimana dilakukan suatu perancangan website Fakultas Keguruan dan Ilmu Pendidikan.

\subsubsection{Metode Penelitian}

Metode yang digunakan dalam penelitian ini adalah metode waterfall dengan Sumber data yang digunakan dalam penelitan ini terdiri dari 2 (dua) jenis:

a. Data Primer

Merupakan sumber data yang diperoleh langsung dari sumber asli. Dalam data primer ini ada dua teknik yang dilakukan. Observasi dilakukan dengan mendatangi langsung Fakultas Keguruan dan Ilmu Pendidikan Universitas Victory Sorong. Wawancara dilakukan dengan mewawancarai Dekan FKIP Universitas Victory Sorong. 


\section{b. Data Sekunder}

Merupakan sumber data penelitian yang diperoleh peneliti secara tidak langsung melalui media perantara. Data sekunder diperoleh melalui sumber-sumber informasi seperti buku, referensi atau website.

\subsubsection{Metode Pengembangan}

Metode penelitian yang digunakan dalam penulisan ini menggunakan model waterfall.

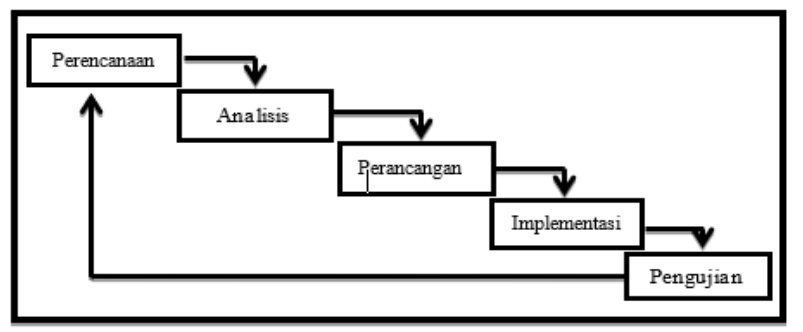

Gambar 2.1 Metode waterfall

1. Tahap perencanaan

Tahap paling awal pada penelitian ini yang merencanakan proses pembuatan suatu sistem agar berjalan secara sistematis.

2. Tahap Analisis (Analisys)

Tahapan ini menganalisa masalah yang terdapat pada website FKIP, apakah sistem tersebut dapat dikembangkan atau tidak.

3. Tahap Perancangan

Tahap ini merancang kerangka sistem tahapan pembuatan rancangan database, UML, flowchart, use case diagram, activity diagram, Sequence Diagram, dan relasi tabel, dengan menggunakan software Microsoft Office Visio, Rational Rose, dan MySQL.

4. Tahap Implementasi

Mengimplementasikan program yang telah dibuat berdasarkan penelitian tersebut, apakah program ini dapat diterima oleh pengguna atau perlu adanya pengembangan.

5. Tahap Pengujian

Tahap ini adalah akhir dari suatu perancangan sistem, pada tahap ini hasil implementasi program akan diuji coba oleh penguji bertujuan agar aplikasi tersebut dapat dioperasikan dengan baik dan dapat diterima oleh user.

\section{3 Analisis Kebutuhan Sistem}

\subsubsection{Kebutuhan Perangkat Keras}

Untuk menjalankan program aplikasi ini digunakan satu unit laptop dengan spesifikasi sebagai berikut :
a. Lenovo-46T3TKV.
b. processor Intel(R) Core(TM) i5-7200u.
c. CPU @ 2.50GHz 2.70 GHz, RAM 4,00 GB. 


\subsubsection{Kebutuhan Perangkat Lunak}

Untuk menjalankan spesifikasi perangkat lunak yang digunakan untuk program ini adalah :
a. Windows 10 pro 64-bit.
b. XAMPP versi 2,5.
c. PhpMyAdmin versi 3.4.5 Documentation.
d. Adobe Dreamweaver CS6.
e. Rational Rose 2006 enterprise edition.

\subsection{Perancangan Sistem}

\subsubsection{Flowchart}

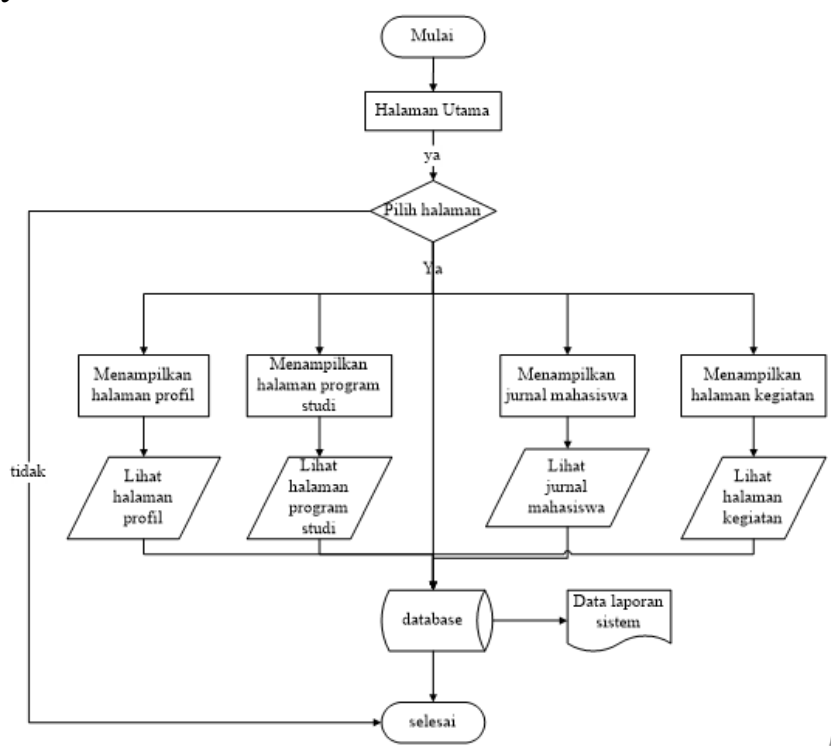

Gambar 2.2 Flowchart Sistem

Gambar 2.2 merupakan flowchart user yang mana hanya dapat melihat isi website tersebut.

\subsubsection{UML (Unified Modeling Language)}

a. Use Case Diagram Admin 


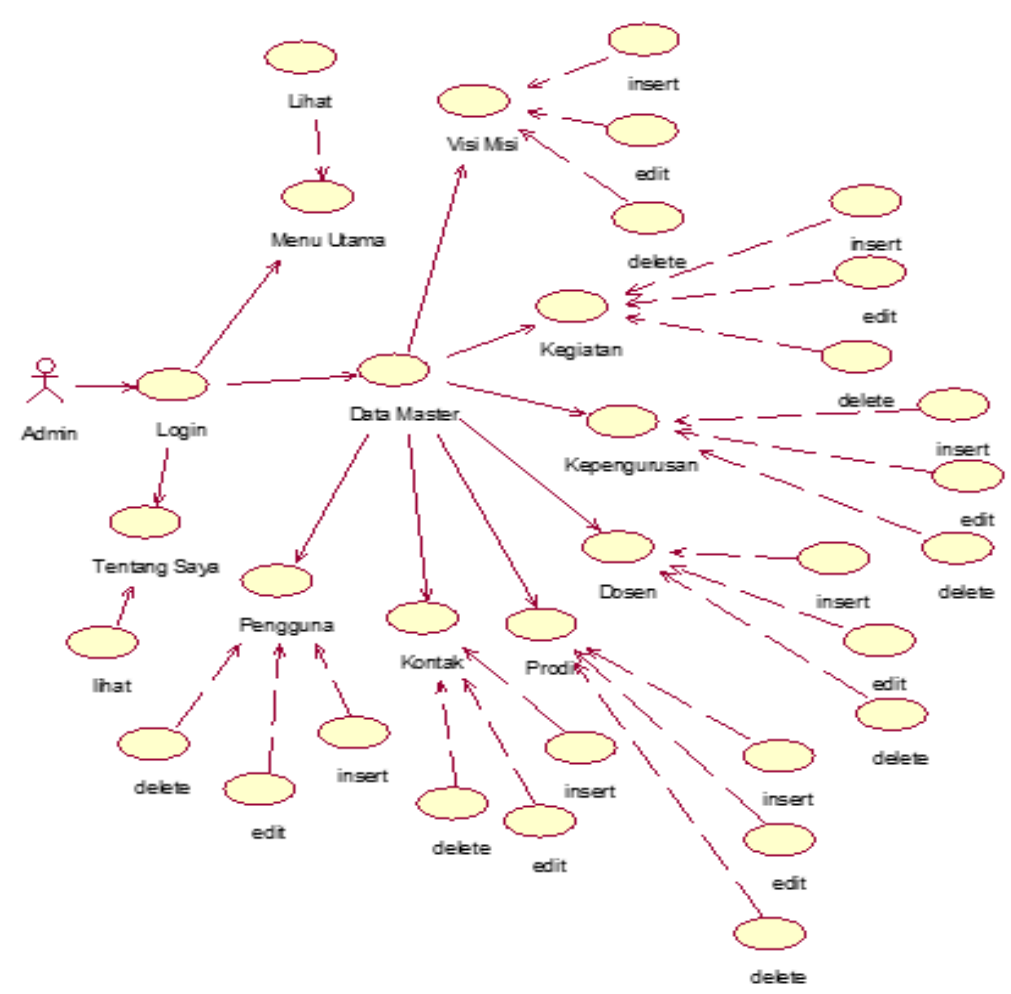

Gambar 2.3 Use Case Diagram Admin

Gambar 2.3 menjelaskan admin mengelola 7 (tujuh) data antara lain, menu utama, visi misi, kepengurusan, dosen, prodi, kontak, pengguna.

\section{b. Activity Diagram Admin}

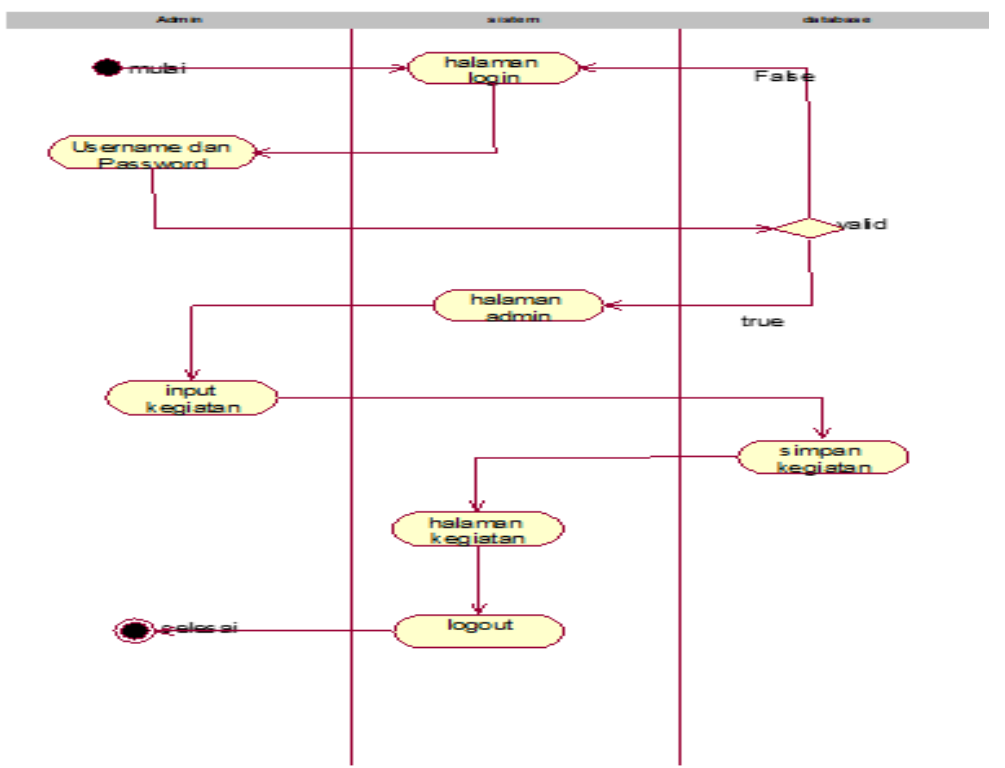

\section{Gambar 2.4 Activity Diagram Admin}

Gambar 2.4 admin melakukan login kemudian sistem meminta untuk masukkan username dan password. Setelah memasukan username dan password valid akan masuk di halaman home kemudian admin akan menginput data. Dalam menginput data-data yang sudah diinput akan masuk ke laporan dan admin dapat melihat laporan tersebut. Setelah itu admin dapat logout dari system. 
c. Sequence Diagram Admin

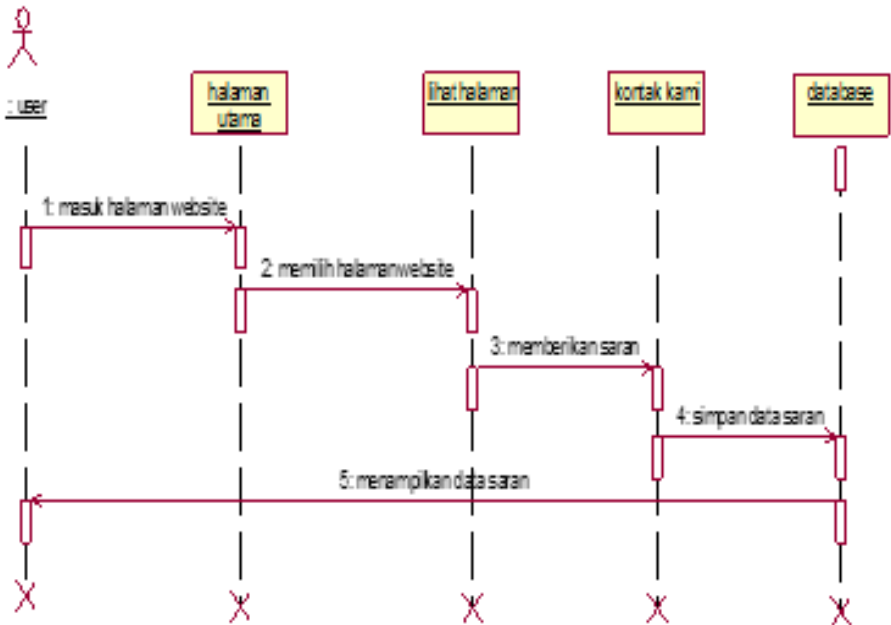

Gambar 2.5 Sequence Diagram User

Gambar 2.5 menunjukkan sequence diagram user, user dapat mengakses halaman utama. Setelah user telah melihat halaman utama maka user dapat memilih menu-menu yang terdapat dihalaman utama, selanjutnya jika user ingin memberikan kritik dan saran bisa langsung menambahkan pada menu kontak kami, ketika sudah selesai diinputkan, maka akan tersimpan di database.

\subsubsection{Perancangan Basis Data}

1. Perancangan Tabel

Tabel 2.1 Perancangan Tabel Dosen

\begin{tabular}{|c|c|c|c|}
\hline Nama & Tipe & $\begin{array}{c}\text { Panjang } \\
\text { Nilai }\end{array}$ & Ket \\
\hline IdDosen & Int & 15 & $\begin{array}{c}\text { Primary } \\
\text { key }\end{array}$ \\
\hline Nama & Varchar & 100 & - \\
\hline NIDN & Varchar & 25 & - \\
\hline Alamat & Varchar & 100 & - \\
\hline Telp & Varchar & 15 & - \\
\hline Jabatan & Varchar & 30 & - \\
\hline Ruangan & Varchar & 15 & - \\
\hline Keterangan & Varchar & 150 & \\
\hline
\end{tabular}

Tabel 2.2 Perancangan Tabel Pengguna

\begin{tabular}{|c|c|c|c|}
\hline Nama & Tipe & $\begin{array}{c}\text { Panjang } \\
\text { Nilai }\end{array}$ & Ket \\
\hline KodeUser & Varchar & 12 & $\begin{array}{c}\text { Primary } \\
\text { key }\end{array}$ \\
\hline Nama & Varchar & 50 & - \\
\hline
\end{tabular}




\begin{tabular}{|c|c|c|c|}
\hline Jabatan & Varchar & 25 & - \\
\hline Password & Varchar & 12 & - \\
\hline
\end{tabular}

Tabel 2.3 Perancangan Tabel Prodi

\begin{tabular}{|c|c|c|c|}
\hline Nama & Tipe & $\begin{array}{c}\text { Panjang } \\
\text { Nilai }\end{array}$ & Ket \\
\hline IdProdi & Int & 11 & $\begin{array}{c}\text { Primary } \\
\text { key }\end{array}$ \\
\hline Kategori & Varchar & 50 & - \\
\hline Keterangan & Varchar & 250 & - \\
\hline Petugas & Varchar & 50 & - \\
\hline
\end{tabular}

Tabel 2.4 Perancangan Tabel Visi Misi

\begin{tabular}{|c|c|c|c|}
\hline Nama & Tipe & $\begin{array}{c}\text { Panjang } \\
\text { Nilai }\end{array}$ & Ket \\
\hline Idvm & Int & 11 & $\begin{array}{c}\text { Primary } \\
\text { key }\end{array}$ \\
\hline Kategori & Varchar & 50 & - \\
\hline Keterangan & Varchar & 250 & - \\
\hline Petugas & Varchar & 50 & - \\
\hline
\end{tabular}

\subsection{Perancangan Interface}

\section{Sketsa Interface Admin}

\section{Gambar 2.7 Sketsa Interface Admin}

Gambar 2.7 merupakan rancangan antarmuka halaman login dari sistem yang akan di bangun seperti gambar diatas.

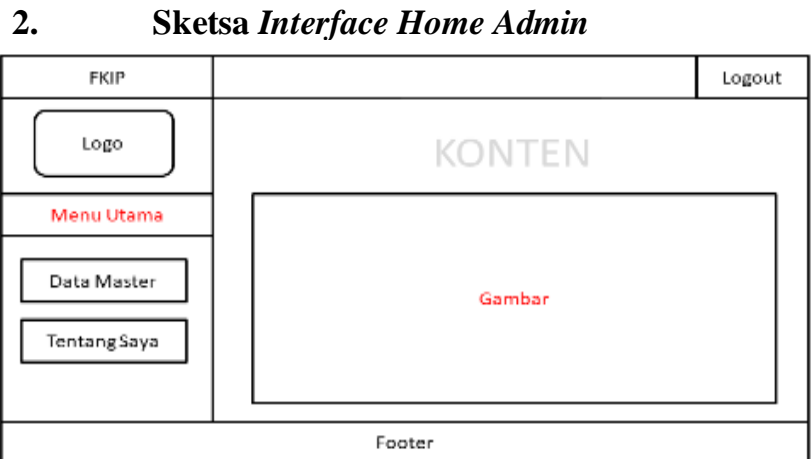

Gambar 2.8 Sketsa Interface Home Admin

Gambar 2.8 merupakan rancangan antarmuka halaman menu utama admin dari sistem yang akan dibangun. 


\subsection{Sketsa Interface Home User}

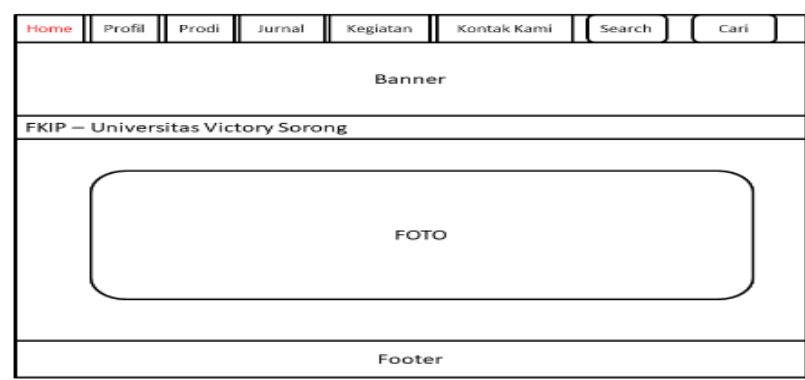

Gambar 2.9 Sketsa Interface Home User

Gambar 2.9 adalah rancangan antarmuka user yang merupakan tampilan halaman home

\section{Sketsa Interface Kegiatan User}

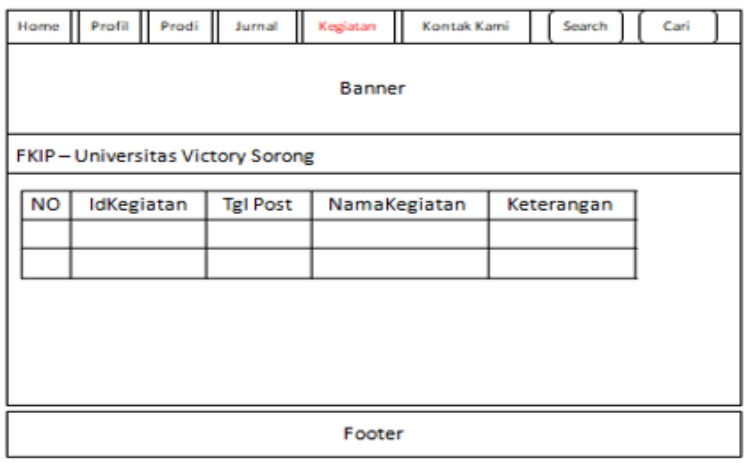

Gambar2.10 Sketsa Interface Kegiatan User

Gambar 2.10 adalah rancangan antarmuka user yang merupakan tampilan halaman kegiatan.

\section{HASIL DAN PEMBAHASAN}

\subsection{Hasil}

Implementasi sistem merupakan kumpulan dari beberapa elemen yang telah didesain ke dalam bentuk pemrograman untuk menghasilkan suatu tujuan yang dibuat berdasarkan kebutuhan.

\section{Interface Halaman Login}

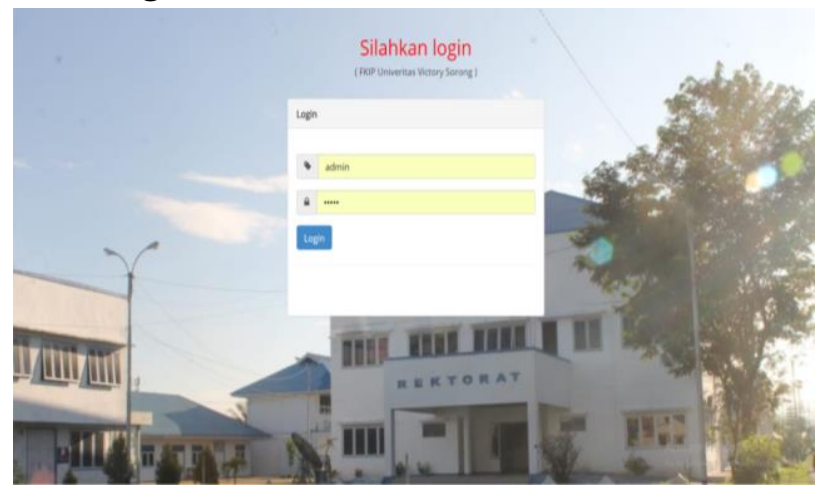


Gambar 3.1 Halaman Interface Login

Gambar 3.1 merupakan halaman interface login yang dapat mengakses sistem adalah admin.

2. Tampilan Awal Interface Admin

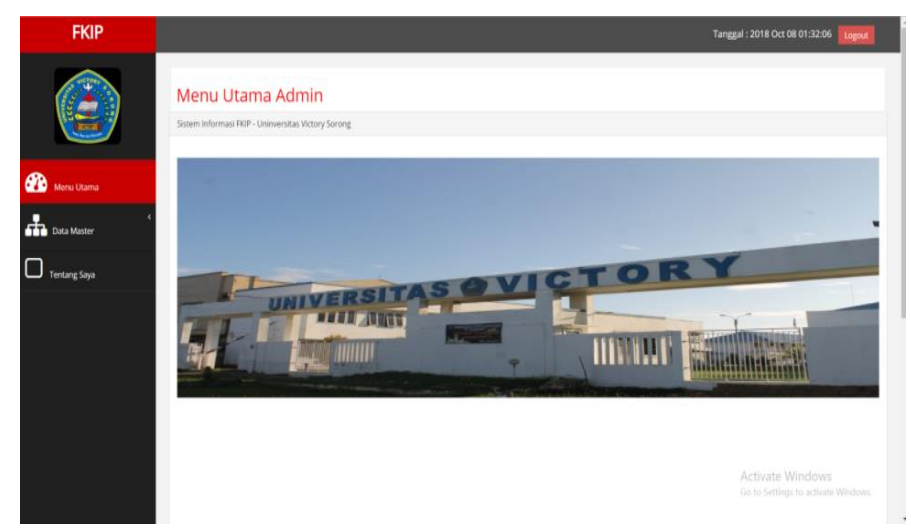

Gambar 3.2 Tampilan Awal Interface Admin

Gambar 3.2 merupakan tampilan awal interface admin adalah halaman menu utama (home) admin, yang berupa gambar.

\section{Tampilan Interface Home User}

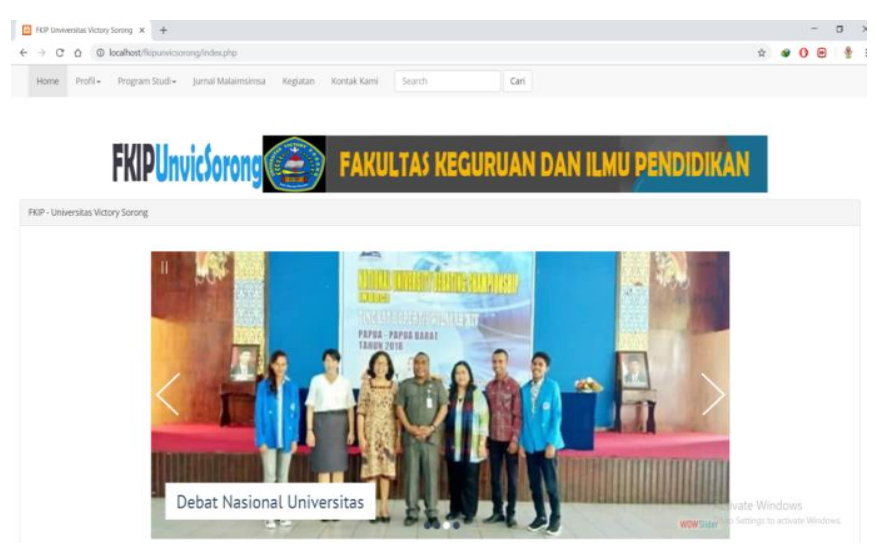

Gambar 3.3 Tampilan Interface Home User

Gambar 3.3 tampilan interface home user ini adalah halaman utama user, yang terdapat sekilas foto-foto aktifitas FKIP. 
4. Tampilan Interface profil

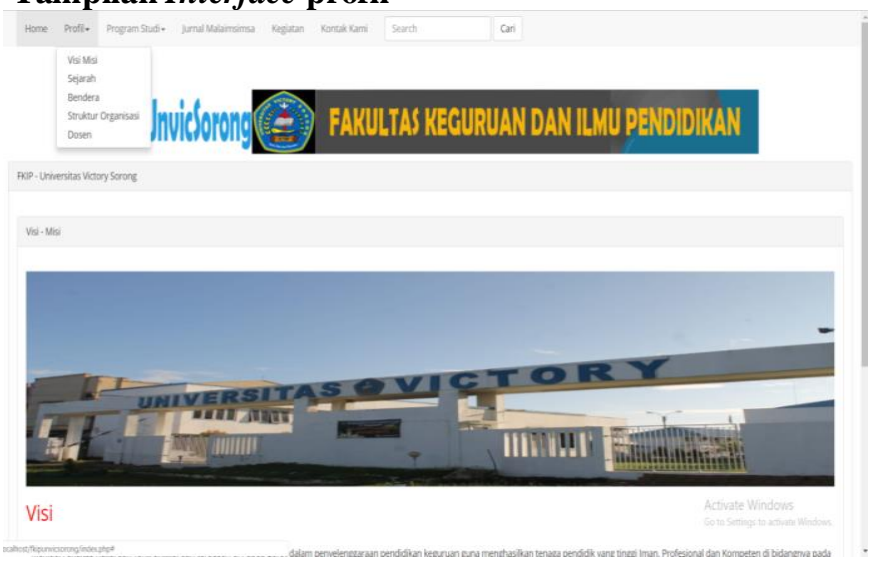

Gambar 3.4 Tampilan Interface profil

Gambar 3.4 merupakan tampilan interface profil, di dalam menu profil terdapat visi misi FKIP, sejarah FKIP, bendera dan arti dari bendera FKIP, struktur organisasi dan biodata dosen-dosen.

\section{Tampilan Interface Program Studi}

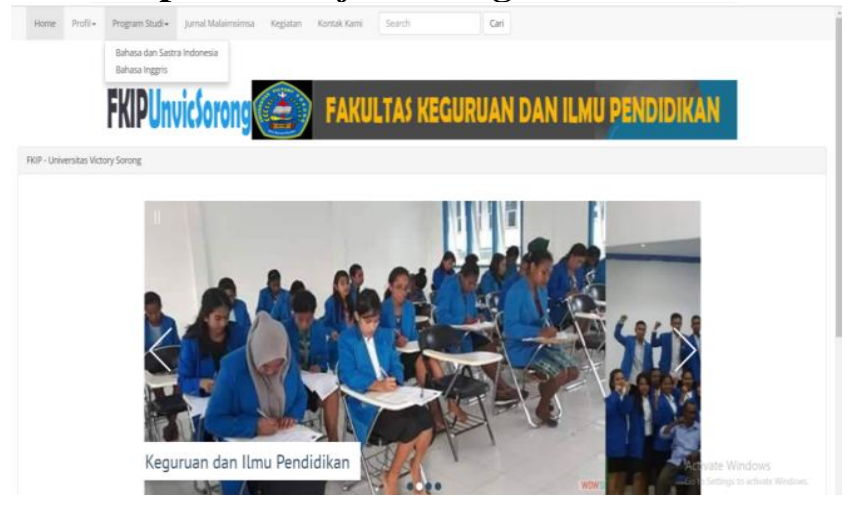

Gambar 3.5 Tampilan Interface Program Studi

Gambar 3.5 berisi alamat halaman situs prodi Pendidikan Bahasa dan Sastra Indonesia dan Pendidikan Bahasa Inggris.

\section{Tampilan Interface Jurnal Malaimsimsa}

FNPUNuicorong (E) FAKULTAS KEGURUAN DAN ILUU PENDIDIKAN

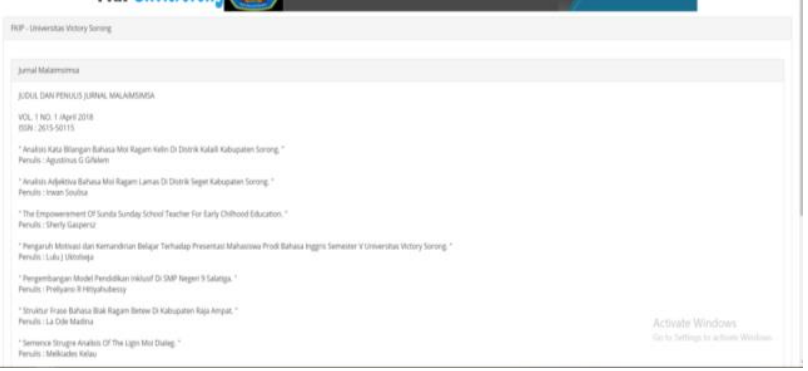

Gambar 3.6 Tampilan Interface Jurnal Malaimsimsa 
Gambar 3.6 merupakan tampilan menu jurnal Malaimsimsa yang berisi penulis dan judul jurnal.

\section{Tampilan Interface Kegiatan}

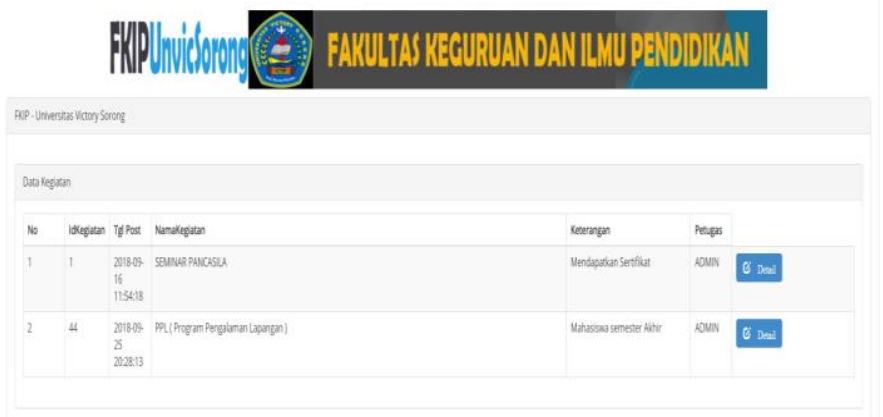

Gambar 3.7 Tampilan Interface Kegiatan

Gambar 3.7 merupakan tampilan menu kegiatan yang berisi kegiatan-kegiatan yang dilakukan oleh FKIP.

8. Tampilan Interface Kontak Kami

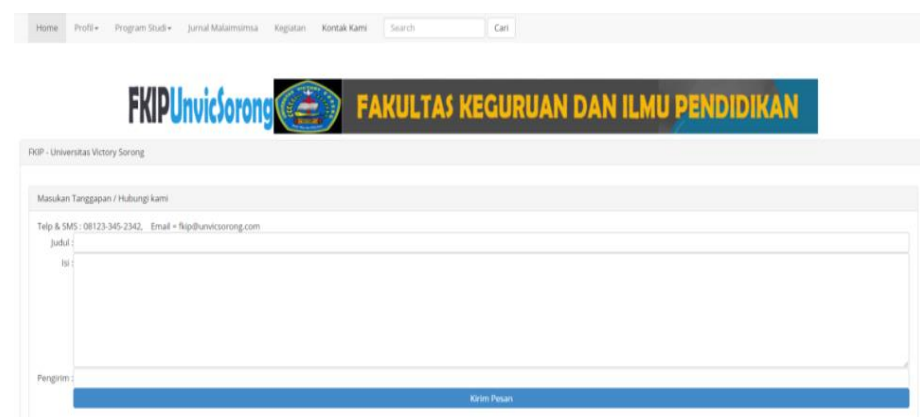

Gambar 3.8 Tampilan Interface Kontak Kami

Gambar 3.8 merupakan tampilan menu kontak kami, berfungsi bila user ingin memberikan saran dan kritik terhadap website FKIP.

\subsection{Pembahasan Listing Program}

\section{Kode Program Koneksi Database}

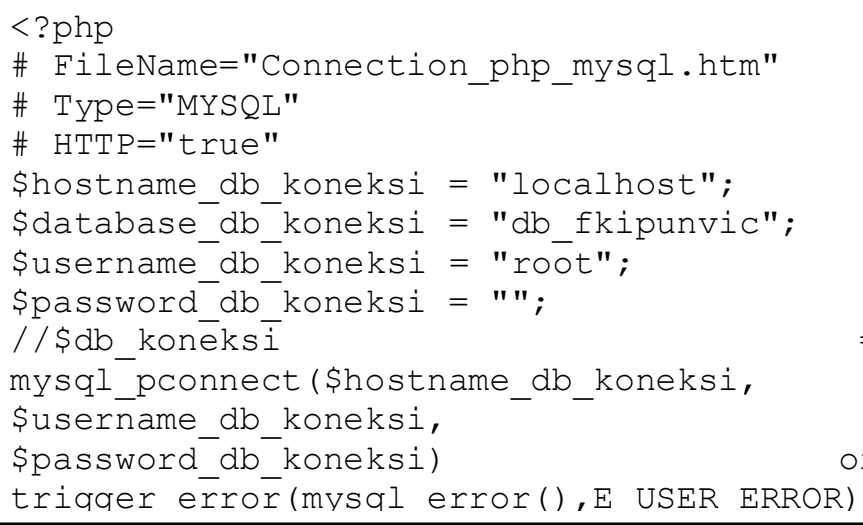

Kode Pogram 3.1 Koneksi database 


\section{KESIMPULAN}

Berdasarkan penjelasan yang dikemukakan pada Bab I hingga Bab III maka dapat diambil kesimpulan sebagai berikut :

1. Website ini dapat memberikan informasi yang jelas dan akurat mengenai Fakultas Keguruan dan Ilmu Pendidikan Universitas Victory Sorong.

2. Website ini dapat menjadi nilai tambah bagi Fakultas Keguruan dan Ilmu Pendidikan Universitas Victory Sorong.

\section{DAFTAR PUSTAKA}

Firdaus, Iqbal., Riyanto. 2016. "Perancangan Website Pemerintah Desa Sebagai Media Penyebaran Informasi Bagi Masyarakat Dengan Metode Waterfall". Jurnal Sainstech Politeknik, Volume.2, Nomor.6, pp. 34-40.

Gordon, B. Davis. 1991. Kerangka Dasar Sistem Informasi Manajemen Bagian 1. PT. Pustaka Binamas Pressindo. =Jakarta: PT Pustaka Pressindo

Handoko, Sigit Giri. Bambang Eka Purnama, Sukadi. 2016. Pembuatan Website Pada Upt Pusat Kesehatan Masyarakat Desa Kalak. Jurnal Evolusi. Volume 4, Nomor 2, pp. $1-8$.

Hariyanto, Bambang. 2004. Sistem Manajemen Basis Data. Informatik. Bandung: Informatika

Heriberty, Elisa Grace. 2014. Black-Box Testing. Bekasi: kompas

Jeffrey L., Whitten., Dittman, Kevin C., Bentley, Lonnie D. 2004. Metode design dan analisa Sistem Bibliografi ed.6, Yogyakarta: Andi Offset

Jogiyanto.HM.1990. Analisis \& Disain Sitem Informasi. Yogyakarta: Andi Offset

Jogiyanto, H.M. 2005. Analisa dan Desain Sistem Informasi : Pendekatan Terstruktur Teori dan Praktik Aplikasi Bisnis. Yogyakarta: Andi Offset

Pressman, 2015. Rekayasa Perangkat Lunak.Yogyakarta: Andi

Pujantoko Yoga. 2015. "Pembuatan Website SMA Negeri 1 Pracimantoro Menggunakan PHP dan MySQL“. Tugas Akhir. Surakarta: Universitas sebelas Maret

Sutarman. 2003. Membangun Aplikasi Web dengan PHP dan MySQL. Yogyakarta: Graha ILmu 